\title{
Preliminary survey of the distribution of four potentially zoonotic parasite species among primates in Sri Lanka
}

\author{
M.A. Huffman ${ }^{1 *}$, C.A.D. Nahallage ${ }^{2}$, H. Hasegawa ${ }^{3}$, S. Ekanayake ${ }^{4}$ L.D.G.G. De Silva ${ }^{4}$ and \\ I.R.K. Athauda ${ }^{4}$ \\ ${ }^{1}$ Primate Research Institute, Kyoto University, Inuyama, Japan. \\ ${ }^{2}$ Department of Sociology and Anthropology, Faculty of Humanities and Social Sciences, University of Sri Jayewardenepura, Gangodawila, \\ Nugegoda. \\ ${ }^{3}$ Department of Biology, Faculty of Medicine, Oita University, Japan. \\ ${ }^{4}$ Department of Parasitology, Faculty of Medical Sciences, University of Sri Jayewardenepura, Gangodawila, Nugegoda.
}

\begin{abstract}
The occurrence of four parasitic species of zoonotic potential, Entamoeba coli, Entamoeba histolytica / dispar, Trichuris sp. and hookworm was investigated in the toque macaque, grey langur and the purple-faced langur at 32 sites across Sri Lanka. The study was carried out during the rainy season months of February - March in both 2007 and in 2009 and in December of 2010. 93 faecal samples were collected from 49 monkey troops at representative locations in altitudinal /climatic zones across the country where toque macaques (58 samples), grey langurs (21 samples) and purple-faced langurs (14 samples) naturally occur. Overall, the most common parasitic species found in all three primates were Trichuris sp. (28\%) and E. coli $(25 \%)$. Notably, hookworms were present in $23 \%$ of the grey langur samples and $33 \%$ of the toque macaque samples but absent in the purple-faced langur samples collected. Statistically significant variability in the prevalence levels across altitudinal/climatic zones was noted for toque macaques. Overall, group prevalence values in toque macaques decreased with increasing altitude; the highest values were found in the intermediate to arid lowland zones, and were lowest in the upland wet zone. Only Trichuris sp. and hookworm were found (13\%, $7 \%$, respectively) in the highland/ wet zone. Molecular analysis will be necessary to genetically type the parasite species before drawing firm conclusions about the status of zoonotic transmission between humans and non-human primates in the country. However this study highlights the need to systematically survey the human parasite population in areas where primates are commonly found to harbour these parasite species.
\end{abstract}

Keywords: Country-wide survey, E. coli, E. histolytica/dispar, hookworm, Trichuris sp., zoonoses.

\section{INTRODUCTION}

It is known that $27.5 \%$ of all parasites found in wild primates, have also been reported in humans (Pedersen et al., 2005). Given the genetic relatedness of non-human primates with humans, the potential for zoonotic transmission between them is expected to be high in areas of close contact (Wolfe et al., 1998). Five species of non-human primates occur in Sri Lanka; the toque macaque (Macaca sinica), the grey langur (Semnopithecus priam thersites), purple-faced langur (Semnopithecus vetulus), and two slender loris species (Loris tardigradus, Loris lydekkarianus) (Molur et al., 2003). With the exception of $S$. priam and L. lydekkerianus, all are endemic species classified as endangered or critically endangered (Dela, 2007; Rudran, 2007; Nahallage et al., 2008).

Periodic reviews of the parasitic zoonoses in Sri Lanka have been made over the years, and the list of such species is extensive (Dissanaike, $1993 \mathrm{a}, \mathrm{b}$; 2002). According to Dissanaike (1993a, b), of the 33 species of parasitic zoonoses detected in humans in Sri Lanka, 5 species (Balantidium coli, Plasmodium spp., Sarcocystis sp., Bertiella studeri and Echinococcus granulosus) were reported for monkeys presumed to be animal host reservoirs. Gunawardena et al. (2011) have also reported moderate to heavy intensity infections with

\footnotetext{
* Corresponding author (huffman@pri.kyoto-u.ac.jp)
} 
potentially zoonotic nematodes, Ascaris lumbricoides, Trichuris trichiura and hookworm in children living in five districts of the plantation sector, namely, Nuwara Eliya, Ratnapura, Kandy, Badullaand Kegalle. Inahospital in Colombo, Cryptosporidium sp., A. lumbricoides, T. trichiura, Giardia lamblia, Entamoeba histolytica and hookworms were detected and significantly associated with diarrhoea in young children (Perera et al., 1999). The first case of human infection due to B. studeri in Sri Lanka was reported from the Central Province (Edirisinghe \& Kumaranjan, 1976). Thereafter, several cases were reported from the Southern Province (Weerasooriya et al., 1988; Karunaweera et al., 2001) and Sabaragamuwa Province (Morawakkorale et al., 2006). According to Karunaweera et al. (2001), B. studeri infection of children in the Dikwella area along the southern coast was 'presumably transmitted from the toque macaque or grey langur'. However, grey langurs are only found in the lowland dry zone, so the toque macaque is more likely to be the reservoir host for these transmissions.

Investigations into the naturally occurring parasites of monkeys in Sri Lanka is limited mainly to the

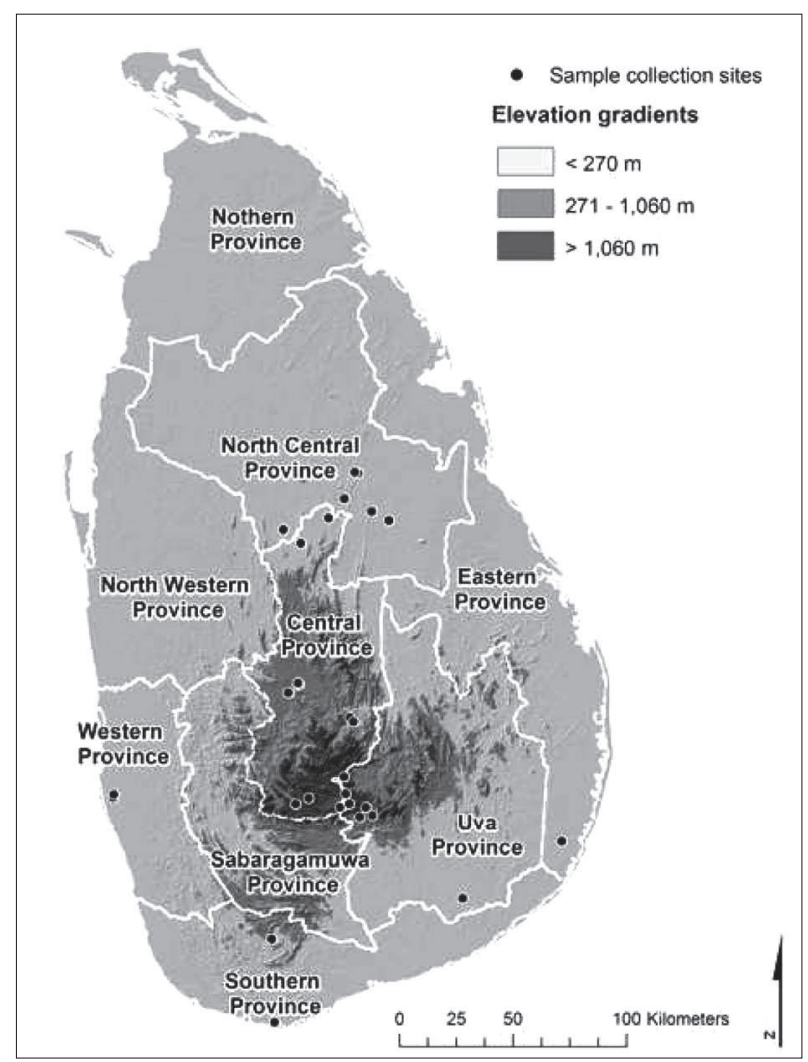

Figure 1: Sites of faecal sample collection archaeological site of Polonnaruwa (Dewit et al., 1991; Ekanayake et al., 2006, 2007), located in the lowland arid zone in the North Central Province. Of the parasite species reported at Polonnaruwa, E. coli was found only in toque macaques and T. trichiura was found in toque macaques, grey langurs and purple-faced langurs. Other primate parasite species of potential anthropozoonotic importance that were not listed by Dissanaike were reported at Polonnaruwa, including Cryptosporidium parvum, E. histolytica /dispar and Entamoeba sp., (Dewit et al., 1991; Ekanayake et al., 2006).

Zoonoses potentially have a significant impact on the health and well-being of both human populations and the co-existing primate populations (Jones-Engel et al., 2004; Pederson \& Fenton, 2006; Gasser et al., 2009). Given the growing degree of contact between humans and monkeys in Sri Lanka due to deforestation, human population growth, expansion of various rural development projects (Nahallage et al., 2008; Nahallage \& Huffman, 2012), and the limited information on the parasites of Sri Lankan primates, there is an urgent need to better understand the status of potential zoonotic infections in monkeys through the monitoring of primate populations across the country. This is important for both human health and primate conservation efforts (Daszack et al., 2000; Patz et al., 2000). To address this need, the occurrence of four typical intestinal parasite, species of zoonotic importance to humans (Entamoeba coli, E. histolytica / dispar, Trichuris sp. and hookworm), known to be shared by many primate species (Huffman \& Chapman, 2009; Lane et al., 2011; Cooper et al., 2012) was investigated by surveying three non-human primate species in Sri Lanka across a range of altitudinal and climatic zones.

\section{METHODS AND MATERIALS}

\section{Study area}

The faecal samples were collected from 32 sites from 49 different primate troops (Table 1, Figure 1). The sites reasonably represent the different altitudinal / climatic zones across the country where these primate species naturally occur. These altitudinal/ climatic zones partition the country by altitude into three peneplains [lowland (0 - 270 masl), upland (270 - 1060 masl) and highland (1060 - 2420 masl)] (Crusz, 1986; Vitanage, 1970), and by trends in rainfall (wet zone: $>1900 \mathrm{~mm} /$ year; intermediate zone: between 1250 - $1900 \mathrm{~mm} /$ year; dry and arid zone: < $1250 \mathrm{~mm} /$ year) (Beenaerts et al., 2010). 
Table 1: Collection sites, elevation, altitudinal / climatic classification and the number of samples collected from three primate species across Sri Lanka

\begin{tabular}{|c|c|c|c|c|c|c|c|}
\hline Province & District & Site & $\begin{array}{l}\text { Elevation } \\
\text { (masl) }\end{array}$ & $\begin{array}{l}\text { Altitudinal / } \\
\text { climatic zone }\end{array}$ & $\begin{array}{c}\text { Toque } \\
\text { macaque } \\
(\mathrm{N}=58)\end{array}$ & $\begin{array}{c}\text { Grey } \\
\text { langur } \\
(\mathrm{N}=21)\end{array}$ & $\begin{array}{c}\text { Purple - faced } \\
\text { langur } \\
(\mathrm{N}=14)\end{array}$ \\
\hline \multirow[t]{16}{*}{ Central } & \multirow[t]{2}{*}{ Kandy } & Kadugannawa & 373 & Upland / Wet & 3 & & \\
\hline & & Kandy & 523 & Upland / Wet & 8 & & \\
\hline & \multirow[t]{3}{*}{ Matale } & Dambulla & 186 & Lowland / Intermediate & 6 & & \\
\hline & & Jathika Namal & & & & & \\
\hline & & Uyana & 600 & Lowland / Intermediate & & 2 & \\
\hline & \multirow[t]{11}{*}{ Nuwara Eliya } & Edition Patana & 1450 & Highland / Wet & 1 & & \\
\hline & & Hakgalla Gardens & 1704 & Highland / Wet & 3 & & 3 \\
\hline & & Horton Plains & 2300 & Highland / Wet & & & 3 \\
\hline & & Keerthibandarapura & 405 & Lowland / Dry & & 3 & \\
\hline & & Ohiya & 1786 & Highland / Wet & 4 & & 1 \\
\hline & & Pathana Kovil & 1134 & Highland / Wet & 3 & & \\
\hline & & Pattipola & 1990 & Highland / Wet & & & 1 \\
\hline & & Peradeniya & 492 & Upland / Wet & 4 & & \\
\hline & & Ratkarawwa & 1145 & Highland / Wet & 1 & & \\
\hline & & Sita Eliya Kovil & 1760 & Highland / Wet & 1 & & \\
\hline & & Wewakele Temple & 690 & Upland / Wet & 1 & & \\
\hline \multirow[t]{6}{*}{ North Central } & \multirow[t]{6}{*}{ Polonnaruwa } & Kaudulla NP & 75 & Lowland / Dry & 1 & 1 & \\
\hline & & Minneriya NP & 131 & Lowland / Dry & 3 & 2 & \\
\hline & & Giritale & 106 & Lowland / Dry & 4 & 4 & \\
\hline & & Polonnaruwa & 56 & Lowland / Dry & & & 1 \\
\hline & & Sigiriya Junction & 300 & Lowland / Dry & & 2 & \\
\hline & & Galoya & 97 & Lowland / Dry & & 2 & \\
\hline \multirow[t]{2}{*}{ Subaragamuwa } & \multirow[t]{2}{*}{ Ratnapura } & Uda Walawa & 97 & Lowland / Dry & 4 & 3 & \\
\hline & & Venture Estate & 1281 & Highland / Wet & 1 & & \\
\hline \multirow[t]{3}{*}{ Southern } & Hambantota & Bundala NP & 8 & Lowland / Arid & 1 & 2 & \\
\hline & \multirow[t]{2}{*}{ Matara } & Matara Dhamhalla & 2 & Lowland / Wet & & & 1 \\
\hline & & Matara Thihagoda & 2 & Lowland / Wet & & & 1 \\
\hline \multirow[t]{5}{*}{ Uva } & Badulla & Haldummulla & 1038 & Highland / Wet & 1 & & \\
\hline & \multirow[t]{4}{*}{ Monaragala } & Kataragama Town & 150 & Lowland / Arid & 1 & & \\
\hline & & Kataragama & & & & & \\
\hline & & Vadehitikanda & 391 & Lowland / Arid & 2 & & \\
\hline & & Yala Paranagantota & 100 & Lowland / Arid & 5 & & \\
\hline \multirow[t]{3}{*}{ Western } & \multirow[t]{3}{*}{ Colombo } & Boralasgamuwa & 12 & Lowland / Wet & & & 1 \\
\hline & & Univ. of Sri & & & & & \\
\hline & & Jayawardenepura & 20 & Lowland / Wet & & 2 & \\
\hline
\end{tabular}

\section{Study Subjects}

Four parasite species of zoonotic potential, E. coli, E. histolytica / dispar, Trichuris sp. and hookworm in groups of toque macaque (Sinhalese: rilawa, Tamil: kurangu), grey langur (S: wandura / konda wandura, heli wandura, T: mundi / mundi-kurangu) and purplefaced langur (S: kalu wandura, T: mundi) were the target species of this investigation. These primate species were easily identified by their distinct morphological characteristics (Figure 2). The distribution of each primate species is particular to its ecologically influenced habitat preference. While the toque macaque and purple-faced langur can be found in most of the altitudinal / climatic zones, the grey langur is restricted to lowland dry and arid regions, mainly in the north, east and southeast areas of the country (Nahallage et al., 2008). The toque macaque and grey langur spent much of their time on the ground when moving between feeding sites and / or when resting. In contrast, the purple-faced langur rarely came to the ground, mostly travelling, feeding, resting and sleeping in the trees. 


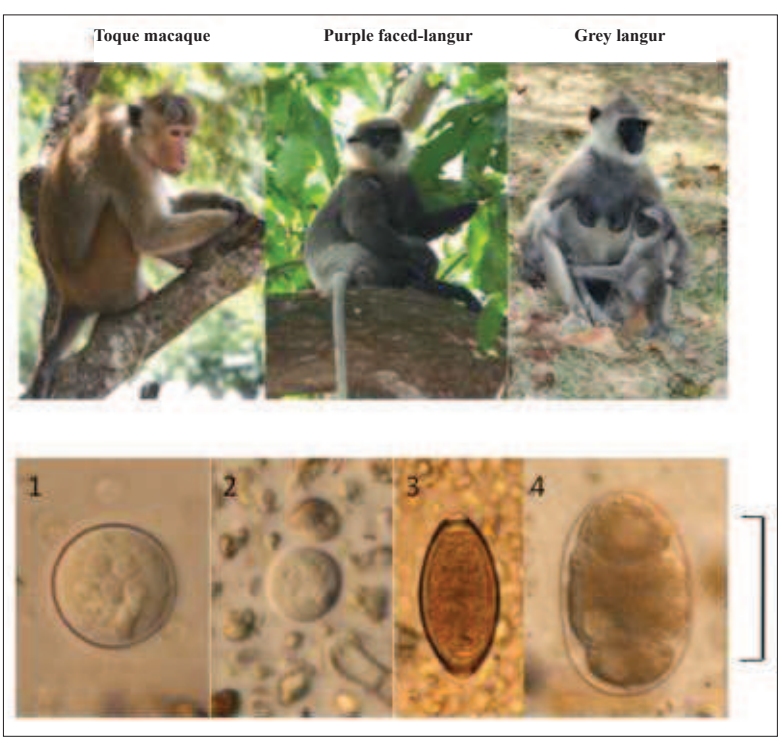

Figure 2: The three primate host species (top) Parasites identified from the feacal samples. 1. Entamoeba coli. 2. Entamoeba histolytica / dispar. 3. Trichuris $\mathrm{sp.}$ 4. hookworm (Scale: $25 \mu \mathrm{m}$ for 1 and 2; $50 \mu \mathrm{m}$ for 3 and 4) (bottom)

The substrate preferences will influence the host's susceptibility to being infected, depending on the transmission and life-cycle characteristics of the infecting organism. All four species of zoonotic potential investigated here have direct transmission routes, i.e. no intermediate host is required for development to the infective stage. Hookworm transmission occurs through penetration of the skin (feet), making travel on the ground the primary substrate of contact (Marquardt et al., 2000). E. coli, E. histolytica / dispar, Trichuris sp. occurs through oral ingestion of cysts or eggs via faecal-contaminated water, food or hands (Marquardt et al., 2000). In this case, infection can occur with or without direct contact with the ground.

\section{Sample collection}

Fresh faecal samples were collected opportunistically during the rainy season months of February - March in 2007 and 2009 and in December 2010. The rainy season was selected to avoid seasonal bias across the study periods, ensuring the best possible comparison of parasite species prevalence. The samples were typically collected while following a group, most often with no other primate species in the area. Two to three samples were collected from each faecal material, and one sample was used for a separate primate phylogenetic study.
Based on these genetic data, in only two cases was our on-site assignment of primate species incorrect; and this was corrected for the current analysis based on the genetic data.

Samples were collected fresh, as noted by consistency and moistness. The top layers (without soil) of the faecal samples $(2-8 \mathrm{~g})$ were collected immediately after defaecation, placed in a sealed vial to prevent contamination and filled up to the top with $10 \%$ formalin and mixed thoroughly, typically within $5 \mathrm{~h}$ after collection. Samples were stored in a dark place in the laboratory until examined.

\section{Examination of faecal specimens}

The faecal specimens were analyzed in the Department of Parasitology, Faculty of Medical Sciences, University of Sri Jayawardenepura, Nugegoda and the Department of Biology, Faculty of Medicine, Oita University, Oita, Japan. Both laboratories used a modified version of the formol-ether concentration method (Ritchie, 1948). Contents of the sediments of the concentrated samples were examined. Identification of cysts of protozoans and eggs of helminths were carried out under the light microscope based on their morphology.

\section{Quantitative analysis}

Since monkeys could not be individually identified, calculation of individual prevalence was not possible. Although it was highly unlikely that the same individual was sampled more than once in a group since the number of samples collected for any one group was usually small, and were collected within a short period of time, the sample prevalence and species richness was calculated. Prevalence was calculated as the percent of samples positive for species X / total number of samples collected. Prevalence was analyzed with respect to host species and altitudinal / climatic distribution. The level of statistical significance was set at $\mathrm{p}>0.05$. Fishers exact test was used for all statistical comparisons.

Permission to conduct this research and for sending the primate faecal samples on a one time basis to Japan for comparative research purposes was granted by the Department of Wildlife Conservation, Sri Lanka. The research was conducted according to local laws and conformed to the ethical standards set out in the Guidelines of Research on Primates in the Wild established by the Primate Research Institute of Kyoto University, Japan (2008). 


\section{RESULTS}

\section{Parasite species prevalence}

In total, 93 faecal samples were collected from toque macaques, grey langurs and purple-faced langurs in their natural habitats from 49 different troops at 32 sites in the Central, North Central, Subaragamuwa, Southern, Uva and Western Provinces (Figure 1). Due to the opportunistic nature of the sampling, there was wide variation in the number of samples obtained from a troop (mean 2.1; range, $1-6$; Table 1). Figure 2 shows the sample prevalence of cysts of E. coli and E. histolytica / dispar and the eggs of Trichuris sp. and hookworm detected in the three primate species. The most prevalent of the potentially zoonotic species found in the pooled data were Trichuris sp. (28\%), hookworm (26\%) and E. coli (25\%; bottom line of Table 2$)$. The prevalence of E. histolytica / dispar (10\%) was less than half of the other species. While Trichuris sp. was most prevalent in the two langur species, hookworm was totally absent from the arboreal purple-faced langur. In contrast, purple-faced langurs had the highest prevalence for E. histolytica / dispar, being 4 and 6 times more prevalent than in toque macaques and grey langurs, respectively. By primate species, the most prevalent potentially zoonotic species was the hookworm for toque macaques, and Trichuris sp. for grey langurs and purplefaced langurs.

\section{Altitudinal / climatic zone prevalence variation in toque macaques}

For the analysis of altitudinal and climatic zone variation in prevalence, adequate data was available only for the toque macaque. Overall trends between the three lowland zones (intermediate / dry / arid) were similar

Table 2: $\quad$ Sample prevalence of four potentially zoonotic species in three primate hosts

\begin{tabular}{|c|c|c|c|c|c|c|}
\hline Host & $\begin{array}{c}\text { E. coli } \\
\text { No. positive }(\%)\end{array}$ & $\begin{array}{c}\text { E. histolytical dispar } \\
\text { No. positive }(\%)\end{array}$ & $\begin{array}{c}\text { Trichuris sp. } \\
\text { No. positive (\%) }\end{array}$ & $\begin{array}{c}\text { Hookworm } \\
\text { No. positive }(\%)\end{array}$ & $\begin{array}{c}\text { Samples } \\
\text { No. examined }\end{array}$ & $\begin{array}{c}\text { Troops } \\
\text { No. examined }\end{array}$ \\
\hline Toque macaques & $15(25)$ & $4(7)$ & $13(22)$ & $19(33)$ & 58 & 28 \\
\hline Grey langurs & $4(19)$ & $1(5)$ & $8(38)$ & $5(23)$ & 21 & 10 \\
\hline $\begin{array}{l}\text { Purple-faced } \\
\text { langurs }\end{array}$ & $4(29)$ & $4(29)$ & $5(36)$ & 0 & 14 & 11 \\
\hline Pooled data & $23(25)$ & $9(10)$ & $26(28)$ & $24(26)$ & 93 & 49 \\
\hline
\end{tabular}

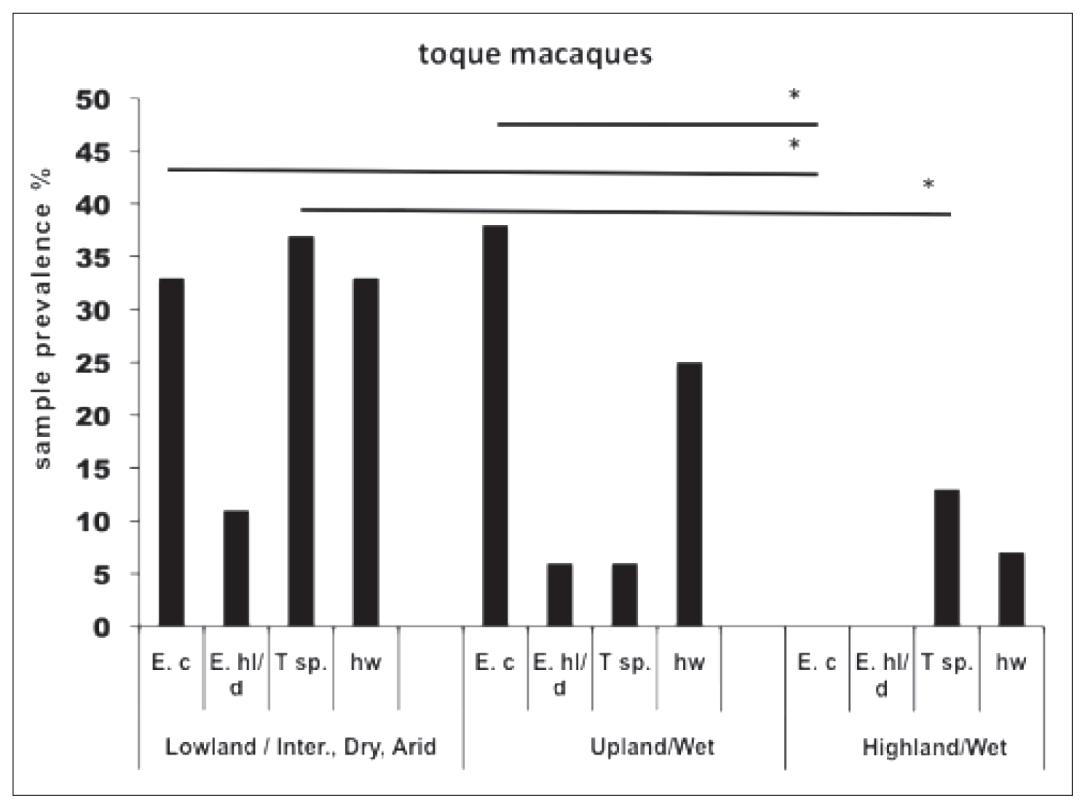

Figure 3 : Inter-altitudinal/climatic variation in prevalence levels of four potential zoonotic species in the toque macaque 
and the data were therefore pooled together into one zone and compared with upland/wet and highland / wet zones, respectively. The overall group prevalence values decreased with increasing altitude (Figure 3 ). The highest prevalence values were noted in the intermediate to arid lowland zones, decreasing in the upland wet zone, with only Trichuris sp. and hookworm found in the highland / wet zone. Significant differences were noted for $E$. coli (highland $<$ lowland, $\mathrm{p}=0.02$; highland $<$ upland, $\mathrm{p}=0.02$, Fisher's exact test), Trichuris sp. (upland $<$ lowland, $\mathrm{p}=0.03$ ) and hookworm (highland $<$ lowland, $\mathrm{p}=0.07$, significant trend). No significant differences were noted for E. histolytica / dispar, but it should be noted that amoeba cysts were not detected in any of the samples collected from the highland wet zone. Compared to the other three species, E. histolytica / dispar prevalence was consistently low across all zones (Figure 3).

\section{DISCUSSION AND CONCLUSION}

The knowledge on potentially zoonotic or otherwise parasitic species in Sri Lankan primates comes mainly from Polonnaruwa in the North Central Province, a lowland, arid habitat (Dewit et al., 1991; Ekanayake et al., 2006; 2007). This is the first extensive multiple site survey of potentially zoonotic species in nonhuman primates to be conducted in Sri Lanka. While the primate hosts' distribution across the country is influenced by altitudinal and climatic factors (Nahallage et al., 2008), at least one, but often two or even all three primate hosts, when found together, were infected with these four species at multiple sites across the country. This reflects the need for a systematic survey of the status of zoonoses of primate origin in the human populations of these areas where human-primate interactions are high (Jones-Engel, 2008; Nahallage et al., 2008; Nahallage \& Huffman, 2012).

As expected, the prevalence of potentially zoonotic parasite infections described for the three primate species was partially explained by the hosts' behavioural habits and the modes of transmission of each potentially zoonotic species (Marquardt et al., 2000). Most noticeable was the prevalence of hookworm, where infections were not detected in the highly arboreal purple-faced langurs, in contrast to the two other more highly terrestrial primate species. The remaining three species, E. coli, E. histolyticaldispar and Trichuris sp. were found in all three primate host species. Interestingly, however, E. histolyticaldispar was least prevalent among the more terrestrial toque macaque and grey langur groups surveyed. Detection of E. histolytica infections among humans is also reportedly on the decrease in Sri Lanka (de Silva et al., 1994). Neither the sample size nor host behaviour alone can easily explain this difference. On the other hand, Ekanayake et al. (2006) reported a much higher prevalence for E. histolytical dispar in toque macaques in Polonnaruwa. In particular individuals in troops exposed to a greater degree of soil substrates $(54 \%)$ are more likely to promote infection of geohelminths. At Polonnaruwa, contamination from local livestock was demonstrated in the case of Cryptosporidium (Ekanayake et al., 2007). In future, intensive sampling of each troop and molecular comparisons will be necessary to better understand the patterns observed in the present study. With a larger sample size from each troop as well as concurrent sampling from livestock and the local human population, it will be possible to determine whether the levels of potentially zoonotic species prevalence are mitigated (Lane et al., 2011) or increased (Nunn \& Altizer, 2006) by the level of contact with humans and their livestock.

Altitude and climatic factors strongly influence the survivability and infectivity of parasitic and commensal organisms with direct transmission life cycles (Anderson, 1992; Marquardt et al., 2000). The statistically significant relationships between higher levels of prevalence and altitudinal and climatic factors found for the toque macaque reflects this, and suggests that the most likely areas for zoonotic transmission in this host species is in warmer drier areas in the lowland zones. Future research should be focused in this aspect. With increasing altitude, the potential for transmission decreased dramatically for these four potentially zoonotic species. The small number of samples currently available for grey langurs and purple-faced langurs precludes meaningful analyses of these trends in their cases. Further work is needed to accurately determine not only the prevalence but also the intensity of infection of these parasites to identify risk areas for zoonotic infection between humans and primates. While the parasitological analyses were restricted to four species of potential zoonotic importance, this analysis clearly shows that a potential for zoonotic transmission between humans and non-human primates exists. Hence, an expanded analysis of a wider range of potential zoonotic agents is warranted. Verification of cross-species transmission, whether it is between different monkey species and/ or between monkeys and humans will require molecular typing of the parasites recovered from monkeys and humans in these areas to clearly determine the potential threat of zoonoses (Gasser et al., 2009). 


\section{Acknowledgement}

Financial support provided by the Environment Research and Technology Development Fund (D-1007) of the Ministry of Environment, Japan, and the Japan Society for the Promotion of Science (JSPS) [Research Grants (C) 22580349 and (C) 23570120] are gratefully acknowledged.

\section{REFERENCES}

1. Anderson R.C. (1992). Nematode Parasites of Vertebrates - Their Development and Transmission. C.A.B International, Wallingford, UK.

2. Beenaerts N., Pethiyagoda R., Ng P.K.L., Yeo D.C.J., Bex G.J., Bahir M.M. \& Artois T. (2010). Phylogenetic diversity of Sri Lankan freshwater crabs and its implications for conservation. Molecular Ecology 19:183 - 196.

3. Cooper N., Griffin R., Franz M., Omotayo M. \& Nunn C.L. (2012). Phylogenetic host specificity and understanding parasite sharing in primates. Ecology Letters 15(12): $1370-1377$.

4. Crusz H. (1986). The vertebrates of Sri Lanka: endemism and other aspects. Report of the Society for Research on Native Livestock 11: $65-80$.

5. Daszak P., Cunningham A.A. \& Hyatt A.D. (2000). Emerging infectious diseases of wildlife-threats to biodiversity and human health. Science 287: $443-449$.

6. Dela J. (2007). Seasonal food use strategies of Semnopithecus vetulus nestor at Panadura and Piliyandala, Sri Lanka. International Journal of Primatology 28: $607-626$.

7. Dewit I., Dittus W.P.J., Vercruysse J., Harris E.A. \& Gibson D.I. (1991). Gastro-intestinal helminthes in a natural population of Macaca sinica and Presbytis spp. at Pollonaruwa, Sri Lanka. Primates 32: 391 - 395.

8. de Silva N.R., de Silva H.J. \& Jayapani V.P. (1994). Intestinal parasitoses in the Kandy area, Sri Lanka. Southeast Asian Journal of Tropical Medicine and Public Health 25: $469-473$.

9. Dissanaike A.S. (1993a). Parasitic zoonoses in Sri Lanka (Part I). Ceylon Medical Journal 38: 150 - 154.

10. Dissanaike A.S. (1993b). Parasitic zoonoses in Sri Lanka (Part II). Ceylon Medical Journal 38: 184 - 7.

11. Dissanaike A.S. (2002). Parasitic zoonoses in Sri Lanka: an update. Ceylon Medical Journal 47: 46 - 47.

12. Edirisinghe J.S. \& Kumaranrajan S.M. (1976). The first record of Bertiella studeri infection in a child from Sri Lanka. Ceylon Medical Journal 22: 137 - 140.

13. Ekanayake D.K., Arulkanthan A., Horadagoda N.U., Sanjeewani G.K.M., Kieft R. \& Dittus W.P.J. (2006). Prevalence of Cryptosporidium and other enteric parasites among wild non-human primates at Polonnaruwa, Sri Lanka. American Journal of Tropical Medicine and Hygiene 74: 322 - 329.

14. Ekanayake D.K., Welch D.M., Kieft R., Hajduk S. \& Dittus W.P.J. (2007). Transmission dynamics of Cryptosporidium infection in a natural population of non-human primates at Polonnaruwa, Sri Lanka. American Journal of Tropical Medicine and Hygiene 77: 818 - 822.

15. Gasser R.B., de Gruijter J.M. \& Polderman A.M. (2009). The utility of molecular methods for elucidating primate-pathogen relationships-the Oesophagostomum bifurcum example. Primate Parasite Ecology: The Dynamics and Study of Host-parasite Relationships (eds. M.A. Huffman \& C.A. Chapman), pp. 47 - 63. Cambridge University Press, Cambridge, UK.

16. Gunawardena K., Kumarendran B., Ebenezer R., Gunasingha M.S., Pathmeswaran A. \& de Silva N. (2011). Soil-transmitted helminth infections among plantation sector schoolchildren in Sri Lanka: prevalence after years of preventive chemotherapy. PLoS Neglected Tropical Diseases 5(9): e1341.

17. Huffman M.A. \& Chapman C.A. (2009). Primate Parasite Ecology: the Dynamics and Study of Host-parasite Relationships. Cambridge University Press, Cambridge, UK.

18. Jones-Engel L., May C.C., Engel G.A., Schillaci M.A., Kyes K., Froelich J., Paputungan U. \& Kyes R.C. (2004). Prevalence of enteric parasites in pet macaques in Sulawesi, Indonesia. American Journal of Primatology 62: 71 - 82.

19. Jones-Engel L., May C.C., Engel G.A., Steinkraus K.A., Schillaci, M.A. Fuentes A., Rompis A., Chalise M.K., Aggimarangsee N., Feeroz M.M., Grant R., Allan J.S., Putra A., Wandia I.N., Watanabe R., Kuller L., Thongsawat S., Chaiwarith R., Kyes R.C. \& Linial M.L. (2008). Diverse contexts of zoonotic transmission of simian foamy viruses in Asia. Emerging Infectious Diseases 14: 1200 - 1208.

20. Karunaweera N.D., Ihalamulla R.L., Wickramathanthri H.K. \& Lamahewage A. (2001). Bertiella studeri: a case of human infection. Ceylon Journal of Medical Science 44: 23 - 24.

21. Lane K.E., Holley C., Hollocher H. \& Fuentes A. (2011). The anthropogenic environment lessens the intensity and prevalence of gastrointestinal parasites in Balinese long-tailed macaques (Macaca fascicularis). Primates 52: 117 - 128.

22. Marquardt W.E., Demaree R.S. \& Grieve R.B. (2000). Parasitology and Vector Biology, $2^{\text {nd }}$ edition. Harcourt Academic Press, MA, USA.

23. Molur S., Brandon-Jones D., Dittus W., Eudey A., Kumar A., Singh M., Feeroz M.M., Chalise M., Priya P. \& Walker S. (2003). Status of South Asian Primates: Conservation Assessment and Management Plan Report, Workshop Report, 2003. Zoo Outreach Organization/CBSG-South Asia, Coimbatore, India.

24. Morawakkorala R.N., Senarathna A.M.R.D., de Alwis A.C.D. \& Abeywardana S.P. (2006). Two cases of monkey tapeworm (Bertiella studeri) infestation from Sabaragamuwa Province. Sri Lanka Journal of Child Health 35: $34-35$.

25. Nahallage C.A.D., Huffman M.A., Kuruppu N. \& Weerasingha T. (2008). Diurnal primates in Sri Lanka and peoples' perception of them. Primate Conservation 23: $81-88$. 
26.Nahallage C.A.D. \& Huffman M.A. (2012). Macaquehuman interactions in the past and present-day Sri Lanka. The Macaque Connection: Cooperation and Conflict Between Humans and Macaques (eds. S. Radhakrishna, M. A. Huffman \& A. Sinha), pp. 135 - 148, Developments in Primatology: Progress and Prospects, Series 43. Springer, New York, USA.

27.Nunn C.L. \& Altizer S. (2006). Infectious Diseases in Primates. Oxford University Press, Oxford, UK.

28.Patz J.A., Graczyk T.K., Geller N. \& Vittor A.Y. (2000). Effects of environmental change on emerging parasitic diseases. International Journal for Parasitology 30: 1395 - 1405.

29.Pedersen A., Poss M., Nunn C.L., Cunningham A. \& Altizer S. (2005). Patterns of host specificity and transmission among parasites of free-living primates. International Journal for Parasitology 35: 647 - 657.

30.Pederson A.B. \& Fenton A. (2006) Emphasizing the ecology in parasite community ecology. Trends in Ecology and Evolution 22: 133 - 139.

31. Perera J., Jayawardene I., Mendis L. \& Abeyratne K. (1999). Intestinal parasites and diarrhoea in a children hospital in Sri Lanka. Ceylon Journal of Medical Science 42: 7 - 12.
32.Primate Research Institute, Kyoto University. (2008). Guidelines for Field Research of Non-Human Primates. Primate Research Institute, Kyoto University, Kyoto, Japan. Available at http://www.pri.kyoto-u.ac.jp/research/ guide-e2008.html.

33. Ritchie L.S. (1948). An ether sedimentation technique for routine stool examination. Bulletin of the US Army Medical Department 8: 326.

34. Rudran R. (2007). A survey of Sri Lanka's endangered and endemic western purple-faced langur (Trachypithecus vetulas nestor). Primate Conservation 22: 139 - 144.

35. Vitanage P.W. (1970). A study of geomorphology and morphotectonics in Ceylon. Proceeding of the Seminar on Geochemical Prospecting Methods and Techniques, UNESCO, New York, USA, pp. $391-406$.

36. Weerasooriya M.V., de Silva D.D.S. \& Mendis D.H. (1988). Bertiella studeri infections in children-report of cases. Proceeding of the $48^{\text {th }}$ Annual Sessions of the Galle Clinical Society, August $26-27$, Galle Faculty of Medicine, p. 17.

37. Wolfe N.D., Escalante A.A., Karesh W.B., Kilbourn A., Spielman A. \& Lal A.A. (1998). Wild primate populations in emerging infectious disease research: the missing link? Emerging Infectious Diseases 4: 149 - 158. 